\title{
Study of Male Factors for Subfertility amongst Rural Couple
}

\author{
Dr. Priyakshi Chaudhry (Resident) ${ }^{1}$, Dr. Deepti Shrivastava(Prof And Head) ${ }^{2}$ \\ R .Hariharan(Prof) ${ }^{3}$, Dr. Arpita Jaiswal (Assos.Prof) ${ }^{4}$, Jnmc, Sawangi ${ }^{5}$ \\ Maharashtra \\ priyakshichaudhry@gmail.com
}

\section{INTRODUCTION}

According to WHO ${ }^{1}$ Infertility, whether male or female, is defined as the inability of a couple to achieve conception or bring a pregnancy to term after a year or more of regular, unprotected sexual intercourse, and there is no other reason (such as breastfeeding or post partum amenorrhea).the term is generally used to denote that the couple has reduced chances to conceive as compared to general population.

Female partner was generally blamed for infertility but, the Greeks were aware of male infertility. Various causes are attributed for infertility and it is proved that infertility is due to many factors, in both male and female It is widely accepted that male factor alone accounts for infertility in about $40 \%$ cases, female factor alone in $40 \%$ of the cases of infertility, and in $20 \%$ cases, there is combined male and female factor. ${ }^{2}$

Semen analysis is a diagnostic tool in the evaluation of the male partners of infertile couples. Careful evaluation of the ejaculate parameters may suggest the possible causes of subfertility and their identification could help to apply appropriate management, if available.

This study aims to assess the semen quality in a rural set up, especially to evaluate the seminal pattern of the male partners of subfertile couples, towards identifying the possible contribution of male factor to overall infertility

\section{AIMS AND OBJECTIVES}

To study the prevalence of various etiological factors responsible for male sub-fertility.

To study the clinical profile of male sub-fertile couple and correlate with etiology

\section{Materials And Methods}

TYPE OF STUDY- PROSPECTIVE CROSS SECTIONAL STUDY

Duration of study :- 2013august -2015 august

Place of study :- DEPARTMENT OF OBSTETRICS AND GYNAECOLOGY JNMC ,AVBRH, DMIMS, WARDHA

Sample size :-100 consecutive couples attending fertility clinic at AVBRH were considered for the purpose of study, after informing them and taking written consent from them, for becoming the part of the study.

\section{Exclusion Criteria}

1) couples not living together. 


\section{Study of Male Factors for Subfertility amongst Rural Couple}

\section{Methodology}

100 subfertile couples attending obstetrics and gynecology opd were included in the study.

Semen collection was done in sterile plastic containers by masturbation after 3 days of abstinence.

Samples were delivered within one hour of collection and analysed by manual method. Analyses were for volume, viscosity, sperm concentration, motility, and morphology, according to WHO guidelines on semen analysis

\section{Result of Semen Analysis According to Who Reference 2000}

Volume $2.0 \mathrm{ml}$

\section{$\mathrm{Ph} 7.2$ or more}

Sperm concentration 20 million spermatozoa per ml or more

Total sperm number 40 million spermatozoa per ejaculate or more

Motility $50 \%$ or more motile (grade $\mathrm{a}^{*}$ and $\mathrm{b}^{* *}$ )or more with progressive

Motility (grade a)with In 60 minutes of ejaculation

Vitality $75 \%$ or more live

White blood cells: fewer than 1 million per ml.

Morphology $15 \%$ or $30 \% * * *$

○ *grade a:a rapid progressive motility(sperm moving swiftly, usually in a straight line)

${ }^{* *}$ grade b: slow or sluggish progressive motility (sperm may be less linear in their progression)

- ${ }^{* * *}$ currently being reassessed by WHO. In the interim, the proportion of normal forms accepted by lab in UK is either the earlier WHO lower limit of $30 \%$ or $15 \%$ based on strict morphological criteria. ${ }^{3}$

\section{OBSERVATion AND RESUlts}

Demographic profile

\begin{tabular}{|l|l|l|}
\hline AGE & $\begin{array}{l}\text { NO OF CASES } \\
\text { N=100 }\end{array}$ & percentage \\
\hline $21-25 y r s$ & 11 & $11 \%$ \\
\hline $26-30 y r s$ & 33 & $33 \%$ \\
\hline $31-35 y r s$ & 27 & $27 \%$ \\
\hline More than 35yrs & 29 & $29 \%$ \\
\hline Total & 100 & 100 \\
\hline Mean age & 28.19 & 32.78 \\
\hline EDUCATION & & \\
\hline Primary & 39 & $39 \%$ \\
\hline Higher & 29 & $29 \%$ \\
\hline
\end{tabular}


Study of Male Factors for Subfertility amongst Rural Couple

\begin{tabular}{|l|l|l|}
\hline Secondary & 32 & $32 \%$ \\
\hline Socio economic status & & \\
\hline Class1 & 6 & $6 \%$ \\
\hline Class 2 & 29 & $29 \%$ \\
\hline Class3 & 41 & $41 \%$ \\
\hline Class4 & 23 & $23 \%$ \\
\hline Class5 & 1 & $1 \%$ \\
\hline Area & & \\
\hline Rural & 53 & 53 \\
\hline Urban & 47 & 47 \\
\hline
\end{tabular}

Distribution Of Cases According To The Duration Of Subfertility

\begin{tabular}{|l|l|l|}
\hline Duration(Years) & No Of Cases & \% \\
\hline $2-3$ Yrs & 38 & 38 \\
\hline$>3-5$ Yrs & 28 & 28 \\
\hline$>5-10$ Yrs & 24 & 24 \\
\hline$>10$ Yrs & 10 & 10 \\
\hline Total & 100 & 100.0 \\
\hline Mean \pm Sd & & $5.84 \pm 5.90$ Years \\
\hline
\end{tabular}

Distribution Of The Cases According To The Frequency Of Coitus

\begin{tabular}{|l|l|l|}
\hline Frequency of coitus/wk & No of cases & $\%$ \\
\hline $1-2 / \mathrm{wk}$ & 42 & 42 \\
\hline $3-4 / \mathrm{wk}$ & 53 & 53 \\
\hline$>4 / \mathrm{wk}$ & 5 & 5 \\
\hline Total & 100 & 100 \\
\hline
\end{tabular}

Distribution Of Cases According To Substance Abuse

\begin{tabular}{|l|l|l|}
\hline Sub Abuse & No Of Cases & $\%$ \\
\hline$\underline{\text { Yes }}$ & $\underline{42}$ & $\underline{42}$ \\
\hline$\underline{\text { No }}$ & $\underline{58}$ & $\underline{58}$ \\
\hline
\end{tabular}

distribution of male cases according to history

\begin{tabular}{|l|l|l|}
\hline SIGNIFICANT MALE HISTORY & NO OF CASES & $\%$ \\
\hline PRE MATURE EJACULATION & 1 & 1 \\
\hline MUMPS & 0 & 0 \\
\hline Trauma/accident & 0 & 0 \\
\hline
\end{tabular}


Study of Male Factors for Subfertility amongst Rural Couple

distribution of male cases according to examination

\begin{tabular}{|l|l|l|}
\hline Male Examination & No Of Cases & $\%$ \\
\hline Varicocoele & 1 & 1 \\
\hline Undescended Testes & 1 & 1 \\
\hline Hernia & 0 & 0 \\
\hline
\end{tabular}

distribution of cases according to seminogram

\begin{tabular}{|l|l|l|}
\hline Seminogram & No Of Cases & $\%$ \\
\hline Normospermia & 63 & 63 \\
\hline Oligospermia & 16 & 16 \\
\hline Azoospermia & 4 & 4 \\
\hline Asthenospermia & 5 & 5 \\
\hline Combine & 12 & 12 \\
\hline
\end{tabular}

Mean age of the men in this study was 28.19 years. Majority i. e $66 \%$ had duration of infertility below 5 years, 24 $\%$ between 5-10 years and there were $10 \%$ with more than 10 years of Subfertility

$42 \%$ men had history of substance abuse like smoking, alcohol, tobacco chewing ,ganja and charas etc.

1 patient had history of pre mature ejaculation. And varicocele and undescended testes were seen in 2 cases on examination.

Out of 100 men studied, 37 were found to have abnormal seminogram. 16 men had oligo spermia,4\% had azoospermia,5\% cases had asthenospermia and combined abnormality was seen in $12 \%$ cases(i.e(pyospermia alone, pyospermia with oligospermia, teratospermia).

\section{DISCUSSION}

In the present study $42 \%$ patients had history of substance abuse and $37 \%$ patients were reported to have abnormal semen parameter. According to a study by Samal et $\mathrm{al}^{4}$, the abnormality of the semen analysis report was found in $35.49 \%, 86.49 \%$ and $53.75 \%$ in smokers, alcoholics and in combinations of these addictions respectively. This shows that cigarette smoking has detrimental effects on spermatogenesis and they thereby impairs fertility. Hence men should be encouraged to stop smoking especially while trying to conceive. Excessive alcohol consumption has been associated with poor reproductive function. Alcohol has profound effects on leydig cell function by reducing testosterone synthesis and its metabolite, acetaldehyde, causing membrane damage and the formation of leydig cell auto antibodies. In the present study 100 males underwent semen analysis $16 \%$ cases reported to have oligospermia followed by $12 \%$ cases had combine abnormality (pyospemia,teratospermia alone or with oligospermia), 5\% cases were reported to have asthenozoospermia,4\% cases had azoospermia which was similar to the study conducted by patel et al ${ }^{5}$ which reported that $23.5 \%$ cases had oligospermia, $50 \%$ cases had azoospermia,17.4\% cases had asthenospermia and $9 \%$ were reported to have combined abnormality. Samal et $\mathrm{al}^{4}$ reported $33.17 \%$ cases had oligospermia,9.89\% cases were reported to have azoospermia and $1.83 \%$ cases reported to have asthenospermia. \%. Thus, education about male infertility and investigating males can be helpful in finding the factor and further management

In another descriptive cross-sectional survey, carried out at the Department of Gynaecology and Obstetrics, Sharif Medical City Hospital, Lahore, from June 2009 to June 2010 by BUTT.F ${ }^{6}$. A total of 500 consecutively consenting male partners of women fulfilling the inclusion criteria between 20 and 40 years of age were 
approached. Semen analysis was performed according to methods and standards defined by the World Health Organisation (WHO). Samples were categorised into normospermia, oligospermia and azoospermia on the basis of sperm count. After exclusion of azoospermic samples, normospermic and oligospermic samples were compared for ejaculated volume, pus cells, motility and morphology. SPSS 10 was used for statistical analysis.Out of the 500 males approached, $104(20.8 \%)$ had to be left out either because of their unwillingness or inability to pass semen. The study sample comprised of 396 (response rate 79.2\%); normospermia was observed in 293 (73.99\%) males, azoospermia in 59 (14.89\%), and oligospermia in 44 (11.11\%). The oligospermic samples had low ejaculated volume, but significantly higher percentage of non-motile sperms $62 \%+/-23.9 \%$ and abnormal morphology 55\% +/- $15.6 \%$ in comparison to normospermic samples (p 0.0001). Asthenospermia was observed in 37 (25.81\%), teratospermia in 11 (3.26\%) and oligoasthenoteratospermia in 4 (9.09\%) of samples.and concluded that Semen analysis is the cornerstone for the evaluation of infertility in men. Sperm concentration, motility and morphology are related to each other, factors that cause deterioration of one of them usually also have negative impact on the other two as well. \%. Thus, education about male infertility and investigating males can be helpful in finding the factor and further management

\section{Conclusion}

Semen analysis remains the single most useful and fundamental investigation for male infertility. Though it not a test of fertility, but it does provide information about abnormalities of sperm count and morphology. Optimal of age of marriage, refraining from addictions, timely medical assistance can help the couples to have successful pregnancy.

\section{REFERENCES}

[1] Cooper Tg,Noonam E,Eckardstein S,Et Al.World Health Organization Reference Values For Human Semen Characterstics.Human.Reprod.Update 2010;16(3):231-45

[2] Shubhada Jajoo, Kanika R. Kalyani ,Prevalence Of Abnormal Semen Analysis In Patients Of Infertility At A Rural Setup In Central India International Journal Of Reproduction, Contraception, Obstetrics And Gynecology 2013 Jun;2(2):161-164

[3] Gutfeld O, Wygoda M, Shavit L, Grenader T (2007). “Fertility After Adjuvant External Beam Radiotherapy for Stage I Seminoma”. The Internet Journal of Oncology 4 (2)

[4] Samal S, Dhadwe K, Gupta U, Gupta NK. Epidemiological Study Of Male Infertility, Indian Medical Gazette, May 2012, 174-80.

[5] Patel M,Jain S et al.Prevelance of different factors responsible for infertility.Res J Recent sci.2012:1:207-2011.

[6] Butt F, Akram N Semen Analysis Parameters: Experiences And Insight Into Male Infertility At A Tertiary Care Hospital In Punjab.J Pak Med Assoc. 2013 May;63(5):558-62.

Citation: Dr. Priyakshi Chaudhry (Resident), Dr. Deepti Shrivastava (Prof And Head), R .Hariharan (Prof), Dr. Arpita Jaiswal (Assos.Prof), Jnmc, Sawangi. "Study of Male Factors for Subfertility amongst Rural Couple. American Research Journal of Gynecology, 1(1): 38-42.

Copyright (c) Dr. Priyakshi Chaudhry (Resident), Dr. Deepti Shrivastava (Prof And Head), R .Hariharan (Prof), Dr. Arpita Jaiswal (Assos.Prof), Jnmc, Sawangi. This is an open access article distributed under the Creative Commons Attribution License, which permits unrestricted use, distribution, and reproduction in any medium, provided the original work is properly cited. 